\title{
ECONOMIA POPULAR SOLIDÁRIA: O QUE É E QUAL O SEU POTENCIAL COMO ALTERNATIVA DE ORGANIZAÇÃO SOCIAL DA PRODUÇÃO NA CRISE DO FORDISMO?
}

Carlos Águedo Nagel Paiva*

\begin{abstract}
Resumo
A Economia Popular e Solidária (Ecopop) passou a ser objeto de crescente interesse teórico e objeto de políticas públicas específicas nas últimas décadas. Contudo, ainda carecemos de uma definição rigorosa de Ecopop. Neste trabalho defendemos o ponto de vista de que toda a produção não-especificamente capitalista deve ser abarcada na categoria Ecopop. Esta definição tem por base a percepção de que a oposição marxiana entre "exército de reserva" (setores informais) e "pequena burguesia" (micro e pequeno empresários), plenamente válida no século XIX, perde substância na etapa especificamente monopolista do capitalismo. Apegar-se a esta clivagem envolve subestimar a expressão econômica da Ecopop, minar alianças políticas importantes em sua defesa, e segmentar as ações públicas objetivas capazes de alavancar o autoemprego e a competitividade da economia não-capitalista.
\end{abstract}

Palavras-chave: economia popular e solidária, economia informal, autoemprego.

\footnotetext{
* Doutor em Economia pela Unicamp, professor do programa de Doutorado e Mestrado em Desenvolvimento Regional da Unisc e pesquisador da Fundação de Economia e Estatística do Rio Grande do Sul.
} 
O marxismo ortodoxo não significa uma adesão a crítica aos resultados de pesquisa de Marx, não significa uma "fé"numa ou noutra tese, nem a exegese de um livro

"sagrado". A ortodoxia em matéria de marxismo refere-se exclusivamente ao método...

Georg Luckács

De uma forma geral, é possível e necessário encontrar formas de quebrar o isolamento da pequena e da micro-empresa e oferecer-lhe possibilidades de cooperação e intercâmbio que aumentem suas probabilidades de êxito. $\mathrm{O}$ nome genérico que damos a esta nova forma de organização econômica é economia solidária.

Paul Singer

\section{Introdução: a relevância da definição de Economia Popular e Solidária (Ecopop)}

Em seus termos mais gerais e ainda abstratos, parece não haver polêmica acerca da definição de Ecopop: trata-se do amplo conjunto de formas não-capitalistas de organização do trabalho e da produção que podem (e devem) ser estruturadas no interior deste sistema com vistas à integração social e produtiva dos agentes redundantes do mesmo.

Contudo, quando se vai além desta caracterização mais geral, buscando detalhar as formas objetivas de manifestação da Ecopop, a polêmica tem início. Mas ela não se encerra neste seu plano inicial: transborda do mesmo para questões tais como: até que ponto uma política de estímulo e defesa da Ecopop pode impactar positivamente na dinâmica mais geral da economia regional?; até que ponto as estruturas produtivas gestadas na política de apoio à Ecopop podem ser competitivas vis-à-vis as estruturas capitalistas e se sustentar a longo prazo sem apoio do estado?; até que ponto a política em defesa da Ecopop pode ser vista como mais do que uma política emergencial e compensatória de inclusão (necessariamente parcial) dos absolutamente excluídos (inclusive de condições mínimas de educação), para ser pensada como uma política de construção objetiva, desde hoje, de uma alternativa não-capitalista de organização social da produção?

Ora, é fácil perceber a importância deste conjunto de questões. O que nem sempre se identifica com clareza é o seu ponto de partida real. Do nosso ponto de vista, o ponto de partida objetivo destas questões, o ponto de partida de toda a polêmica sobre o tema, diz respeito ao papel do microempreendimento no interior da Ecopop. Na realidade, 
o que se discute nos debates sobre o caráter compensatório (e necessariamente parcial e tático) da Ecopop, ou seu caráter central e dinamizador (e, portanto, estratégico) é se os microempreendimentos mercantis rurais e urbanos fazem ou não parte da economia não-capitalista moderna. Mais exatamente, o que se discute aqui é: quem é o novo proletariado e o novo exército industrial de reserva do sistema? E por extensão necessária - quem é a classe dominante e exploradora e qual sua inserção social objetiva?

\section{Negação do trabalho assalariado e "revivescência" do microempreendimento}

Do nosso ponto de vista, a crise do fordismo é a crise do assalariamento de massas; é a crise do emprego capitalista. Uma crise já percebida por muitos - dos jovens em busca do primeiro emprego, às vítimas das terceirizações e doronsizings de cada dia; mas nem sempre adequadamente percebida pelos gestores das políticas públicas, líderes sindicais e representantes políticos da classe trabalhadora. $\mathrm{O}$ problema de fundo, contudo, é que mesmo quando estes agentes acordam para a "estruturalidade" da crise do fordismo, não alcançam entender que o horizonte de ocupação posto para os novos redundantes do sistema é o microempreendimento urbano.

Ou não é este o destino de uma parcela crescente de trabalhadores? Trabalhadores que são, hoje, ex-metalúrgicos, ex-bancários, ex-funcionários públicos, defenestrados da produção e do assalariamento a cada privatização, a cada "choque de competitividade", a cada downsizing, a cada PDV (Ponto de Vista). Defenestrados do assalariamento na medida em que o capital descobre que contratar (e explorar) microempresários independentes (ou organizados em "cooperativas autônomas", tanto faz) é muito mais lucrativo - porquanto gerador de uma mais-valia maior - do que contratar assalariados formais e organizados em sindicatos combativos.

A verdade é que o capital já descobriu que seu poder de exploração não depende diretamente da relação assalariada. Uma descoberta que os melhores teóricos do marxismo já haviam feito ${ }^{1}$. Mas que não alcança ser feita por aqueles que tomam a palavra escrita dos clássicos do marxismo como "autos de fé".

Afinal, para os marxistas do século XIX - a começar pelo próprio Marx - o pequeno produtor independente, o pequeno burguês (no sentido estrito desta categoria), era um resquício da ordem mercantil característica da crise do feudalismo. Era um sujeito destinado à
${ }^{1}$ Entre nós, Caio Prado Jr. é o grande crítico do formalismo que hipostasia o assalariamento como a única forma de exploração consistente com a valorização capitalista (PRADO JR., 1970, 1974). Vale observar que, se a crítica de Caio Prado foi apropriada de forma equivocada pela historiografia anti-stalinista mais vulgar (que, para se contrapor ao etapismo, retira historicidade da relação capitalista, acabando por identificá-la a qualquer relação de exploração mediada pela mercadoria), tal fato não retira consistência da mesma. Apenas comprova que o formalismo é uma opção fácil: ele simplifica o complexo e proporciona "âncoras categoriais" que ajudam a sustentar a "fé" e a "clareza" daqueles que não suportam a radicalidade subversiva da história real. 
${ }^{2}$ É bem verdade que o microempreemdimento não é, ainda, economia popular especificamente solidária; mas pode e deve vir a ser se pretender se consolidar como alternativa produtiva de longo prazo. Afinal, a competitividade e sustentabilidade dos microempreendimentos é função de sua capacidade de formação de redes formais e informais voltadas à ação econômica (compras conjuntas, propaganda conjunta, etc.) e/ou política (defesa da concorrência, conquista de políticas públicas diferenciadas, etc.). Além disso, todo o microempreendimento de base familiar já introduz relações produtivas não-mercantis, prenhe das relações de solidariedade especificamente familiares. O que permite a inclusão genérica dos microempreendimentos de base familiar (seja ele organizado em rede ou não) no rol das atividades da Ecopop. Neste sentido, estão absolutamente corretos os militantes dos movimentos de sem-terra e militantes dos distintos movimentos de apoio à agricultura familiar, que incluem a pequena produção rural independente entre as atividades típicas da Ecopop.

${ }^{3} \mathrm{E}$ de se observar que as referências não gratuitas - à Microsoft, AOL, Apple, Netscape e Google podem ser esgrimidas como contra-argumento à tese aqui defendida. $\mathrm{E}$ isto na medida em que estas empresas surgiram como "pequenos empreendimentos" e se transformaram rapidamente em estruturas monopolistas ou semimonopolistas. A ideologia dominante resgata estes eventos excepcionais - somente abertos a empreendimentos organizados em indústrias radicalmente novas e dinâmicas e em mercados capitalistas hegemônicos (EUA, Japão, etc.) - e os "normaliza" (torna-os "norma"), na busca de demonstrar que "qualquer microempreendimento pode vir a se transformar em uma empresa global de expressão monopolista". Os críticos (pseudo)ortodoxos da identificação do microempreendimento mercantil a uma forma não-(mais-)capitalista de organização compram, então, a destruição pelo poder competitivo do grande capital. E - mais do que isto - era um sujeito que fazia uma crítica saudosista e conservadora (objetivamente retrógrada) ao desenvolvimento da ordem monopolista.

Sem dúvida! E, como usual, a análise sociológica de Marx é inatacável. Mas não é a-histórica. E hoje, o pequeno produtor independente é um outro sujeito. Não é mais o herdeiro do artesanato mercantil do feudalismo em crise. Este - onde existiu - já desapareceu há muito. E é sempre bom lembrar que ele nunca existiu em nosso país, que nunca teve, nem feudalismo, nem burguesia revolucionária aos moldes europeus. Por isto mesmo, o microempresário contemporâneo é outro sujeito social, com outra extração histórica e de classe, e com outro horizonte político potencial (ou, mesmo, atual). $\mathrm{Na}$ verdade, o microempreendimento de hoje é a forma objetiva de manifestação da forma latente do exército industrial de reserva (Cf. MARX, 1983, cap. 23). E, enquanto tal, o microempreemdimento hoje é a forma mais simples e imediata de manifestação daquela economia não-capitalista que caracterizamos como economia popular².

$\mathrm{Na}$ realidade, vivemos hoje o paroxismo da ordem monopolista. Caminhamos rapidamente para um sistema onde sobreviverão apenas algumas poucas companhias automobilísticas independentes no mundo. A cada dia uma nova fusão bancária intercontinental redefine a hierarquia dos grandes conglomerados financeiros. A Microsoft só deixa de ser considerada monopolista porque a AOL (que comprou a Time Warner, que havia comprado a CNN) passou a ser dona da Netscape, disponibilizando na rede um concorrente do Windows Explorer. Um movimento que gerou a reação da Microsoft, expressa em suas tentativas de associação com a Apple e com a Google ${ }^{3}$.

Pergunta-se: num mundo como este, faz sentido pensar que o verdureiro da esquina, que trabalha doze horas por dia no balcão com sua esposa, sogra e filho, é um "explorador capitalista" só porque contratou um auxiliar para fazer as entregas da tarde? Sim, dizem os formalistas pretensamente ortodoxos. Está escrito na obra maior de Marx: "o capital [...] só surge onde o possuidor dos meios de produção e de subsistência encontra o trabalhador livre como vendedor de sua força de trabalho no mercado" (MARX, 1983, p. 141) ${ }^{4}$. Não, respondem os verdadeiros materialistas históricos. Está escrito no "Método": "até as categorias mais abstratas [...] são [...] igualmente produto de condições históricas, e não possuem plena determinação senão a partir dessas condições e dentro dos limites dessas" (MARX, 1982, p. 17).

Mas por que esta polêmica acerca da historicidade das relações sociais e o conteúdo do assalariamento nos dizem respeito? Porque, quando se apoia o desenvolvimento de microempreendimentos mercantis, 
mesmo que os mesmos tenham por base o trabalho familiar, não há como impedir o desenvolvimento (ainda que eventual) de relações de assalariamento em seu interior. O que, de um ponto de vista formalista, implicaria o reconhecimento de que estes empreendimentos podem ser (ou mesmo já são!) empreendimentos capitalistas e exploradores. Vale dizer: eles não seriam estratégicos no interior de um projeto socialista de desenvolvimento, e o apoio aos mesmos não significaria mais do que uma aliança tática entre "socialistas" e "pequenos burgueses" no enfrentamento conjunto do inimigo principal de ambos: a burguesia monopolista.

Discordamos radicalmente desta leitura. E para enfrentá-la radicalmente é preciso demonstrar a falsidade de sua raiz: a identificação des-historicizada entre assalariamento e exploração. O que nos coloca frente à responsabilidade de discutir o sentido e os fundamentos da exploração para Marx ${ }^{5}$.

\section{O que é exploração?}

Em seus termos mais simples e mais gerais a categoria marxista de exploração diz respeito a um processo de intercâmbio socialmente instituído onde determinados agentes são levados a ceder, de forma sistemática e socialmente compulsória, mais-trabalho do que recebem em contrapartida.

A importância desta caracterização se encontra no fato de que ela enfrenta quatro incompreensões (que se desdobram em críticas, tão equivocadas, quanto recorrentes), ao esclarecer que: 1) a exploração (por oposição à expropriação) pressupõe alguma relação estável de intercâmbio de trabalho e/ou de produtos do trabalho ${ }^{6}$; 2) inequivalências assistemáticas ${ }^{7}$ não configuram exploração; 3) a exploração pode ocorrer (e ocorre) mesmo na ausência de assalariamento ou de relações mercantis ${ }^{8}$; e last, but not least, 4) como a medida da exploração é a troca desigual de trabalho, aquelas disparidades sistemáticas de apropriação por parte de agentes intercambiantes que estão baseadas em disparidades sistemáticas das contribuições em trabalho não envolvem qualquer exploração? .

É fácil perceber que os dois últimos desdobramentos da definição de exploração apresentada acima são fundamentais para nossa discussão. O terceiro desdobramento esclarece que, não raramente, relações sociais de produção que aparecem ${ }^{10}$ como relações puramente solidárias são relações de exploração. E na crise contemporânea do fordismo, o desenvolvimento de relações de exploração com aparência de rela-
REVISTA GRIFOS 53

ideologia do "small is beautifull and able to become big" para reafirmar a perspectiva pré-marxista de demonização de toda a organização produtiva que não se estruture formalmente sobre normas e princípios do igualitarismo mais extremo.

${ }^{4}$ Note-se que nesta passagem (como em todas as demais em que tal tese é esgrimida) Marx afirma que, tão somente quando há assalariamento, há capitalismo (em sentido puro e pleno, acrescentaria Caio Prado). Mas não diz que sempre que há assalariamento, há capital e exploração.

${ }^{5}$ Esta discussão é objeto de praticamente todo o terceiro capítulo, bem como da última seção do capítulo quarto de meu trabalho de doutorado (PAIVA, 1998). A discussão que se segue é uma síntese extremamente rápida de alguns desenvolvimentos destes dois capítulos.

${ }^{6}$ É preciso ter claro que nem todo o intercâmbio é mercantil e, por isso mesmo, nem todo o intercâmbio é aparente. Lévi-Strauss (e todo o estruturalismo moderno) não elevou o "Ensaio sobre a dádiva" de Mauss à condição de esteio da etnologia científica gratuitamente: este trabalho desvenda e teoriza a dimensão "intercambiante" (porquanto prenhe de exigências de reciprocidade) da troca de "presentes" que caracteriza as sociedades iletradas pré-mercantis. Vale a pena lembrar, contudo, que a teorização hegeliana acerca da relação entre senhor e servo como uma relação de mútua dependência já anuncia (e transcende) a construção de Mauss. No mesmo sentido, as recorrentes observações de Marx acerca das ilusões características das diversas formas de relação de exploração (no escravismo a ilusão é de que o trabalhador entrega o seu trabalho sem qualquer reciprocidade, enquanto no capitalismo a ilusão é de que todo o trabalho realizado pelo assalariado é pago) esclarece que, na verdade, não existe exploração sem 
troca (ainda que desigual), sem intercâmbio (ainda que não equivalentes). Vale observar, por fim, que ao se reconhecer o caráter estrutural da desigualdade-inequivalência na troca se está reconhecendo, de fato, que esta troca comporta uma dimensão de compulsoriedade, de circunscrição de liberdade. O problema é não tomar esta circunscrição real como negação do intercâmbio; como índice de inexistência de troca. A incapacidade de perceber o elemento de intercâmbio que acompanha a exploração é o que caracteriza a leitura idealista e voluntarista deste processo. Afinal, se não há nenhum intercâmbio na exploração, se só há exação neste processo, este só pode se sustentar pela violência dos dominadores e pela apatia dos dominados. E, neste caso, toda a tarefa da "vanguarda revolucionária" é iluminar e instigar a moblização das massas.

${ }^{7} \mathrm{Como}$ as inequivalências que caracterizam as trocas firmadas entre produtores de mercadorias flex price (vale dizer, que apresentam instabilidade de oferta e demanda e alta flexibilidade de preços), bem como as inequivalências que caracterizam a troca entre produtores capitalistas que operam com composições orgânicas de capital distintas (o que impõe desvios entre valor e preço e inequivalências em termos de valor, que podem flutuar em qualquer sentido e direção a partir de mudanças tecnológicas imprevisíveis). À diferença destes exemplos de "troca de inequivalente" - cuja marca é a inestabilidade dos agentes superavitários e deficitários em trabalho -, a inequivalência que caracteriza a exploração é absolutamente estrutural. Por isto mesmo, é ela que dá o fundamento para a clivagem marxiana das classes: em sociedades marcadas pelo antagonismo de classes, a classe dominante ou exploradora é aquela que recebe, de forma estrutural e ções solidárias tem sido crescente. Esta "solidariedade exploradora" impõe-se, internamente, em diversas organizações produtivas familiares baseadas na exploração do trabalho de crianças e demais dependentes incapacitados para a autonomia, e impõe-se externamente a partir de relações de microempresas e cooperativas organizadas por ex-assalariados (terceirizados compulsoriamente) com grandes empresas compradoras que limitam de forma sistemática a autonomização real de seus "parceiros" produtivos.

De outro lado, o quarto desdobramento nos ajuda a ver que, se a relação de assalariamento se estruturar de tal forma a garantir a apropriação pelo assalariado do fruto integral do seu trabalho, esta relação não é uma relação de exploração. Este tipo de assalariamento é raro, mas existe. Ocorre, por exemplo, naquele assalariamento que, de um lado, garante que a microempresa familiar opere na escala mínima competitiva (alavancando a produtividade sistêmica e gerando benefícios distribuíveis entre todos), e, de outro, garante para o assalariado, para além do salário, a aprendizagem de uma prática trabalhante que ele exercitará autonomamente a partir do momento em que sua formação assim o permitir.

Mais uma vez, é fácil perceber que o perfil do assalariamento definido acima para o microempreendimento contemporâneo corresponde às relações de trabalho características do artesanato feudal. Uma similaridade que poderia gerar duas críticas: a de a-historicidade da construção, e a de subordinação à "ideologia da solidariedade" que ocultava a exploração efetiva subjacente às relações entre "mestres e aprendizes". Enfrentemo-las, começando pela última.

Sem dúvida, a relação de formação profissional feudal permitia e ocultava todo um conjunto de relações de exploração. As enormes e crescentes exigências de qualificação dos aprendizes impunham - não gratuitamente - um período de aprendizagem demasiado longo, que era altamente lucrativo para o mestre. Porém, se se entende a determinação que viabilizava a exploração na ordem urbana medieval, também se entende como é possível enfrentá-la: retirando do mestre (e das guildas) o poder para deliberar as condições de autonomização do aprendiz e sua efetiva constituição como produtor autônomo.

Aliás, este controle é, justamente, o busílis da questão. Em qualquer sociedade mercantil, a condição da exploração é a circunscrição (e, no limite, o impedimento) de que o produtor direto (o trabalhador) se transforme em produtor autônomo. Uma circunscrição/impedimento que, no capitalismo, é definida pela elevada escala mínima de produção e pelo volume de recursos (que, ato contínuo, transformam-se em capital) necessário para a montagem de um "negócio". Exploremos esta ideia. 


\section{Novos horizontes da luta contra a exploração capitalista na virada do milênio}

Como nos ensinaram Hegel e Marx, explicitar um problema com clareza, organizá-lo na forma de uma questão, é definir as condições de sua solução. É um "quase-resolvê-lo". E Marx explicitou o problema central da ordem burguesa e forneceu a chave para sua solução. A chave para o enfrentamento da exploração é a apropriação coletiva dos meios de produção.

Perfeito! Só o que fica por definir é: o que se entende por (e como se organiza a) "apropriação coletiva”? Este é o problema maior. Um problema para cujo enfrentamento Marx contribuiu mais de forma negativa (esclarecendo qual - a despeito da aparência em contrário não é a solução), do que de forma propriamente positiva (indicando qual seria a solução efetiva). E a importante contribuição negativa de Marx (que, mais do que nunca, importa resgatar) é a de que as soluções estatizantes não são soluções efetivas. Para Marx, o Estado é a expressão superior e a síntese da luta de classes. Ele não é um fim. O verdadeiro fim é a destruição da luta de classes e, por consequência, do próprio Estado.

Ora, os limites deste enfrentamento negativo da questão da apropriação coletiva são sobejamente conhecidos, e seria demasiado pretensioso querer enfrentar aqui este enorme problema histórico. Mas, talvez, não seja demais seguir o conselho de Marx e contribuir para a organização deste problema. O que envolve enfrentá-lo a partir de questionamentos que abdiquem da abstração em prol da identificação das condições históricas concretas dentro das quais se realiza, hoje, a exploração e a dominação capitalista, bem como a resistência às mesmas. Do nosso ponto de vista, isto envolve enfrentar duas questões distintas igualmente importantes, quais sejam: 1) se - no bojo da moderna onda de "terceirização", franchising, downsizing e "busca do foco" que torna as grandes empresas cada vez mais "virtuais" - o próprio capital "socializa" a propriedade do equipamento físico sem socializar as condições de apropriação de lucros, o que é imanente ao capital (enquanto fundamento da apropriação de sobretrabalho) e que, de fato, tem de ser socializado hoje se se quer enfrentar a exploração?; 2) este "quê" pode, de alguma forma, ser socializado hoje a partir de ações políticas de governos de partidos socialistas em sociedades ainda burguesas?

Ora, este duplo questionamento nos traz de volta à crítica deixada em suspenso acima acerca da pretensa a-historicidade da forma de assalariamento potencialmente não exploratória, e que atualizaria as sistemática, mais trabalho do que cede, enquanto a classe trabalhadora, subordinada ou explorada é aquela que cede, de forma estrutural e sistemática, mais trabalho do que recebe.

${ }^{8}$ Aliás, ao longo da história da humanidade, a exploração com base no assalariamento é uma exceção notável. Vulgarmente, a exploração se impõe a partir de outras formas de relação social de subordinação da força de trabalho que, não raramente (dado o tensionamento inerente à perenização de relações de intercâmbio desigual), têm a aparência de relações solidárias. Este é o caso de todas as sociedades onde a exploração se associa à dominação religiosa e/ou à fetichização do "inimigo externo" e das necessidades de "proteção" dos trabalhadores. De forma mais geral, a aparência de solidariedade é fundamental em sistemas não mercantis que apresentam produtividade relativamente (e não absolutamente) baixa, porquanto a baixa produtividade limita a sustentação de um exército permanente apto a garantir a exploração pela mera violência. O revolucionário sistema capitalista (onde a igualdade formal e a naturalização das relações sociais definida pela forma-valor oculta a exploração) é o primeiro sistema social que permite a exposição nua e crua dos interesses que subjazem à "solidariedade". Uma transparência impossível nas sociedades (e comunidades) pobres, organizadas em torno da carência de todos e de cada um.

${ }^{9}$ À diferença das demais incompreensões listadas e enfrentadas acima - que caracterizam as leituras (e críticas) conservadoras de Marx - esta é uma incompreensão que caracteriza as leituras de esquerda pré-marxistas. Desta perspectiva, os homens são "naturalmente" iguais e merecem (por lei "divina" ou "natural"; tanto faz) usufruir das mesmas condições de vida independentemente de suas contribuições e/ou necessidades particulares. 
Como Marx bem o sabia, o fundamento deste igualitarismo vulgar (que é intolerante com toda e qualquer diferença, e luta por sufocar qualquer manifestação de gênio, qualquer dom artístico, qualquer proposta inovativa, qualquer ousadia, qualquer heresia) é a inveja, e não a ciência. Para Marx e para os marxistas - a teoria da exploração é uma teoria científica, e o seu fundamento é a abstração crescente do processo de trabalho que permite a comparação objetiva das contribuições sociais de cada um. Só há exploração quando a apropriação em trabalho difere sistemática e estruturalmente das contribuições em trabalho; não quando as apropriações são diferenciadas em função de contribuições diferenciadas.

${ }^{10} \mathrm{Não}$ cabe ingressar aqui na complexa dialética entre essência e aparência. Mas vale a pena lembrar que, de uma perspectiva dialética, a aparência nunca é inteiramente falsa. A aparência é, sempre, a primeira forma de manifestação da essência. A ideologia não é mais do que a absolutização dogmática desta dimensão "meramente" aparencial. A contra-ideologia ainda ideológica é a pura negação da aparência. O resgate científico (vale dizer, dialético-totalizante) do ser não é mais do que o reconhecimento de sua complexidade/ contraditoriedade.

${ }^{11} \mathrm{Ou}$, antes: "pseudo-ortodoxa", porquanto apegada à "letra do livro sagrado", e não ao materialismo histórico e dialético. A este respeito, veja-se o ensaio "O que é o marxismo ortodoxo?", em Luckács (1974, p. 15 et seq.).

${ }^{12}$ Uma vantagem de escala é aquela diretamente relacionada com o tamanho físico da estrutura produtiva. Um exemplo típico é a de relações mestre-aprendiz do artesanato feudal. É possível construir relações deste tipo no atual estágio do desenvolvimento capitalista?

A resposta "marxista ortodoxa" 11 é: não! Afinal - como se sabe Marx via a grande indústria como a forma superior de produção, negando qualquer possibilidade da pequena produção independente concorrer com as vantagens de escala que garantiam enormes vantagens de produtividade/custo para a grande produção.

E Marx estava certo. Não há mais espaço para a pequena produção independente! Só que há - e muito - para a pequena produção articulada! Um espaço que Marx não percebeu adequadamente. E não o fez porquanto não percebeu adequadamente (nem poderia em seu tempo) a distinção entre "escala" e "escopo"; nem percebeu que, em processos produtivos descontínuos, as vantagens de escala são secundárias vis-à-vis as vantagens de escopo ${ }^{12}$. Uma secundarização que se aprofunda quanto menores forem os custos de transporte e comunicacionais, maiores as exigências de diversidade (ou de "desestantardartização") e de flexibilidade produtiva; e mais intenso for o progresso técnico depressor do valor e das dimensões absolutas do maquinário exigido para a produção competitiva em cada setor específico. Vale dizer: esta é uma secundarização que vem se aprofundando no bojo da revolução técnico-informacional contemporânea ${ }^{13}$.

Vale a pena observar que esta secundarização crescente da escala frente ao escopo (que é o próprio fundamento da crise do fordismo) vem sendo adequadamente percebida e explorada por parte das grandes empresas capitalistas. Assim é que - apenas para dar um exemplo ilustrativo - empresas como a Brown Boveri reduziram suas instalações centrais em Zurique de uma planta de 4.000 empregados para uma planta que ocupa tão somente 200 assalariados (a quase totalidade, lotada nos departamentos de marketing e de P\&D). Ato contínuo, esta empresa pulverizou suas compras de insumos e material por aproximadamente 1.200 unidades empresariais "independentes", boa parte das quais montadas pelos antigos funcionários da Brown Boveri com o apoio desta. Ex-funcionários que deixaram de receber todos os benefícios funcionais e passam a arcar com todas as consequências de eventuais variações na demanda e inflexões tecnológicas depressoras do valor de seus conhecimentos e maquinários. A quem interessar, vale esclarecer que a Brown Boveri ampliou sua lucratividade após esta "modernização solidária”. O mesmo já não se pode dizer do conjunto dos novos "empresários" do setor.

O que cabe perguntar então é: por que os trabalhadores-empresários continuam dependentes da Brown Boveri? E a resposta é: porque eles, sozinhos, não são nada. Eles não podem, sozinhos, construir 
os aparelhos eletroeletrônicos que constroem coletivamente para a Brown Boveri. Além disso, mesmo que se organizassem em rede, não teriam marca, nem pontos de venda, nem estrutura de P\&D.

Mas eles não podem vir a constituir uma rede, com marca, estrutura distributiva e de P\&D próprias? Teoricamente, sim. Mas dificilmente conseguirão sem o apoio resoluto do Estado.

$\mathrm{E}$, ainda mais importante: de uma perspectiva socialista não interessa que as microempresas "terceirizadas" pelas gigantes alcancem se estruturar em rede autonomamente. E isto a despeito de uma tal organização já significar um avanço na luta contra a exploração. Sem dúvida significa. Mas ela equivaleria à organização dos produtores autônomos em "guildas modernas"; onde os "mestres" (leia-se: os microempresários articuladores da rede) poderiam cercear (e, no limite, impedir) a autonomização efetiva de seus (mais do que possíveis, prováveis) aprendizes-assalariados. Não é isto que se quer. O socialismo pressupõe a máxima mobilidade social, a universalização do acesso aos meios de apropriação plena dos frutos do próprio trabalho.

Por outro lado, isto não implica pretender que as redes solidárias de microempresas devam ser objeto de controle absoluto pelo Estado. Isto nos conduziria ao equívoco do estatismo, com seus desvios sobejamento conhecidos de burocratismo e inércia. Não é disso que se trata. Tanto mais na medida em que - como é sempre bom lembrar - as vantagens da organização em rede (que tanto vem seduzindo empresas como a Brown Boveri) vis-à-vis a linha de produção fordista se encontram na flexibilidade de um sistema em que o processo decisional e os custos de adaptação são relativamente pulverizados. Centralizar e controlar de forma autocrática e burocratizada as redes de microempresas é o mesmo que destruir suas vantagens competitivas.

Por isto mesmo, o que se exige é um grau de incidência sobre as redes que inviabilize a rigidificação e fechamento das mesmas ao ingresso de novos trabalhadores qualificados. Trabalhadores cuja qualificação passa - sem se esgotar - pela experiência profissional como "assalariado solidário" no interior das microempresas organizadas. Mas que vai muito mais longe, passando pela efetiva socialização de um ensino técnico-profissional (sempre e necessariamente articulado ao ensino fundamental) de altíssima qualidade, bem como pela ampla disponibilização de micro (e meso) crédito aos trabalhadores interessados em se tornar microempresários.

Com estes três instrumentos - 1) universalização do ensino técnico de alto nível; 2) disponibilização de crédito para todos os trabalhadores no patamar necessário ao ingresso autônomo dos mesmos na produção como gestores desta; e, last but not least; 3) estruturação de centrais hidrelétricas. Usualmente, duas pequenas centrais não geram a mesma energia elétrica (mas menos!) que uma grande central hidrelétrica que represe exatamente o dobro de volume d'água e (por hipótese simplificadora) tenha sido construída com o dobro de material e custos. Por outro lado, vantagem de escopo não é uma vantagem associada ao tamanho físico dos equipamentos e/ou das instalações, mas do fato de que todo um conjunto de custos (de distribuição, propaganda e marketing, compras, contratação, fiscalização, $P \& D$, etc.) são diluídos sobre um conjunto particularmente amplo de unidades produzidas/vendidas. As grandes corporações são multi-plantas, porque se beneficiam mais das vantagens de escopo associadas à unidade, do que das vantagens de escala (associadas ao tamanho mínimo competitivo de uma planta industrial).

${ }^{13}$ Vale esclarecer que não pretendemos generalizar esta secundarização. Por determinações ainda pouco teorizadas e conhecidas, setores industriais não desprezíveis se mostram absolutamente resistentes ao processo de depressão relativa da expressão da escala vis-à-vis o escopo. Nestes setores, as redes de microempresas não se constituem como alternativas competitivas de Ecopop às estruturas produtivas capitalistas. $\mathrm{O}$ que implica dizer que o enfrentamento do controle burguês deste setor não pode passar pela alternativa aqui defendida.

${ }^{14}$ Talvez o sejam. Talvez não. Não chego a ter uma opinião totalmente determinada sobre isto. De qualquer forma, tenho absoluta clareza de que a aparência de solidariedade superior daquelas formas de gestão e propriedade em que a totalidade dos meios de produção é apropriada coletivamente não garante sua superioridade de fato. Desde logo, pode-se argumentar contra algumas cooperativas industriais que elas tendem a preservar a separação entre trabalho inte- 
lectual e manual, falhando na efetiva socialização dos conhecimentos de gestão por parte do conjunto dos trabalhadores. De outro lado, as formas diretamente comunitárias de produção e gestão, se rompem com os limites acima especificados de certas cooperativas, tendem a introduzir circunscrições demasiado apertadas a quaisquer iniciativas individuais e a qualquer diferenciação, caindo em práticas características do "igualistarismo invejoso" tão críticas por Marx. Na verdade, a única vantagem aparente destas formas cooperativas e diretamente comunitárias de organização da produção sobre as redes solidárias de microempresas é que elas facilitam a subordinação da minoria à maioria. $\mathrm{O}$ que - a despeito do que pretenderiam basistas de todos os matizes - é uma dimensão legítima, mas absolutamente insuficiente da democracia. Na verdade (e com o perdão da insistência), é uma dimensão profundamente perigosa quando imposta no interior de comunidades que ainda não superaram a perspectiva "invejosa" de crítica social. Uma situação demasiado comum para ser ignorada. Afinal, como Marx salientava, a inveja é a primeira determinação (inclusive no plano cronológico) da crítica à desigualdade. Mas seu horizonte prático é a do igualitarismo "mesmificador", intolerante para com qualquer manifestação de gênio e personalidade. O que, para Marx, não alimenta a solidariedade efetiva, mas o temor, o controle e a oposição de todos contra todos. redes sob estrita regulação estatal com vistas à efetiva democratização/ socialização de sua gestão, - nós estaremos, de fato e objetivamente, construindo agora uma alternativa não capitalista de organização social da produção apto a se desenvolver como um verdadeiro câncer no interior deste sistema excludente e decadente.

Isto é Ecopop. Mais ainda: esta é a forma de Ecopop que importa privilegiar na atual conjuntura. Porquanto dialoga com as demandas sociais, explora as brechas e contradições do sistema, e abre alternativas efetivamente revolucionárias - e não meramente compensatórias de organização dos "redundantes" e desapropriados do sistema.

Por fim, cabe concluir resgatando o que os desenvolvimentos anteriores já devem ter tornado óbvio: se as redes solidárias de microempresas sob regulação público-estatal são Ecopop (como de fato são, pois se estruturam sobre a solidariedade dos agentes e são incompatíveis com a exploração), elas, evidentemente, não são a única forma possível de Ecopop. De fato, formas cooperativas ou diretamente comunitárias também são Ecopop. E talvez até possa se argumentar que são formas superiores ${ }^{14}$. Só que isto não nos permite pretender que o privilegiamento (para não dizer absolutização) destas formas seja necessário ou mesmo possível. Na verdade, na atual conjuntura do capitalismo mundial, estas formas mais tradicionais de Ecopop padecem dos mesmos limites de que padecem as formas fordistas de organização da produção: falta de flexibilidade gerencial, produtiva e tecnológica. Limites estes que reforçam as resistências ideológicas à sua construção e que deprimem suas potencialidades de funcionarem como respostas dinâmicas à crise contemporânea de emprego. E o que não temos de sobra é tempo!

Por tudo isto, surge desenvolver as redes solidárias de microempresas sob regulação estatal Porque é eficaz na luta emergencial contra a exclusão e o desemprego; porque responde a demandas sociais reais, postas no nível da consciência crítica das massas; porque está ao nosso alcance fazê-lo; e - acima de tudo - porque abre uma alternativa de fato à ordem produtiva burguesa.

\section{Referências}

LUCKÁCS, G. História e consciência de classe. Porto: Escorpião, 1974.

MARX, K. O Capital (Livro 1). São Paulo: Abril Cultural, 1983.

Para a crítica da economia política. São Paulo: Abril Cultural,

1982.

REVISTA GRIFOS - N. 24 -JUNHO/2008 
MAUSS, M. Sociologia e antropologia. São Paulo: Edusp/EPU, 1974.

PAIVA, C. A. N. Valor, preços e distribuição: de Ricardo a Marx, de Marx a nós. Campinas: Unicamp, 1998.

PRADO JR., C. Formação do Brasil contemporâneo. São Paulo: Brasiliense, 1970.

. História econômica do Brasil. São Paulo: Brasiliense, 1974.

\begin{abstract}
The Social and Solidarity Economy (Ecopop) has become subject of growing theoretical interest and subject of specific public policies along the last decades. However, there isn't any rigorous definition of (Ecopop). In this paper we propose a definition: every economic activity that is not specifically capitalist must be considered part of (Ecopop). This definition is constructed on the statement that the Marxian opposition between industrial reserve army (informal sector) and petit bourgeois (shopkeepers) isn't valid nowadays. In my point of view, this opposition leads to the undervaluation of economic expression of (Ecopop), disturbs and poisons important political alliances of distinct groups of excluded, and forbids the construction of a unified public policy in support of non-capitalist economy.
\end{abstract}

Keywords: social and solidarity economy, informal economy, self-employment. 
